\title{
Akt regulates RSK2 to alter phosphorylation level of H2A.X in breast cancer
}

\author{
ZHI-FENG GUO and FAN-LONG KONG \\ Department of Oncology, Section II, Chifeng Municipal Hospital, Chifeng, \\ Inner Mongolia Autonomous Region 024000, P.R. China
}

Received November 28, 2019; Accepted August 13, 2020

DOI: $10.3892 / \mathrm{ol} .2021 .12448$

\begin{abstract}
Histone $\mathrm{H} 2 \mathrm{AX}(\mathrm{H} 2 \mathrm{~A} . \mathrm{X})$ is a variant of the histone H2A family. Phosphorylation of H2A.X is a marker of DNA strand breaks and the presence or absence of H2A.X is closely related to tumor susceptibility and drug resistance. The present study found that the activity of the serine/threonine kinase Akt was negatively associated with H2A.X phosphorylated at the Ser16 site (H2A.X S16ph), but the mechanism of the inverse relationship remains elusive. The aim of the present study was to elucidate the mechanism of action between Akt and H2A.X S16ph and the exact role of this mechanism. Western blot analysis was performed to detect the regulatory association between p-Akt and H2A.X S16ph/p-RSK2, and immunoprecipitation and chromatin immunoprecipitation were performed to prove that Akt, RSK2 and H2A.X combine and interact in human breast cancer cells. The changes of cellular proliferation and migration induced by the interaction of Akt, RSK2 and H2A.X was determined by MTT, soft agar colony formation and cell migration experiments. The effect of interaction of Akt, RSK2 and H2A.X on cancer-promoting genes, such as PSAT-1 was determined via reverse transcription-quantitative PCR analysis. The current study indicated that the serine/threonine kinase ribosomal S6 kinase 2 (RSK2) as a kinase of H2A.X could be phosphorylated by Akt at Ser19 site. Moreover, Akt positively regulated the phosphorylation of RSK 2 to inhibit phosphorylation of H2A.X, thereby affecting the affinity between RSK2 and substrate histone, promoting the survival and migration of breast cancer cells. In conclusion, Akt-mediated phosphorylation of RSK2 regulated the phosphorylation of H2A.X, thereby promoting oncogenic activity. This finding provides new insights to understand the pathogenesis and treatment mechanisms of breast cancer.
\end{abstract}

Correspondence to: Professor Zhi-Feng Guo, Department of Oncology, Section II, Chifeng Municipal Hospital, 1 Middle Section of Zhaowuda Road, Chifeng, Inner Mongolia Autonomous Region 024000, P.R. China

E-mail: zhifangguo_2000@126.com

Key words: serine/threonine kinase ribosomal S6 kinase 2, histone H2AX, Akt, breast cancer, phosphorylation

\section{Introduction}

Breast cancer is one of the most common female malignant tumors in the world (1), which has been proved to be the second leading cause of death by cancer among women worldwide (2). According to statistics, there were 1.67 million new breast cancer cases and 500,000 mortalities worldwide in 2012 (3). Currently, the pathogenesis of breast cancer is not completely understood, but the cause of breast cancer is related to a number of factors including age and breast gland density $(4,5)$. The incidence of breast cancer in women increases with age $(6,7)$, and the incidence of breast cancer in women with high breast density is 4-6 times higher than that in women with low breast density $(8,9)$. Although the treatment of cancer has improved over the years, the current treatment for breast cancer mainly including surgical operation and chemotherapy cannot effectively ameliorate the overall survival of patients with breast cancer because of the metastasis of breast cancer (10). The high mortality of breast cancer is due to the metastasis and drug resistance of breast cancer cells $(11,12)$. About $30 \%$ of patients with breast cancer will have axillary lymph node metastasis and distal organ (stone, liver, lung and brain) metastasis, reducing the survival rate of patients $(13,14)$. During the course of chemotherapy treatment for triple negative breast cancer (TNBC), the chemical resistance of cancer cells may be caused by the disorder of DNA replication, the repair of key enzymes, the change of apoptosis related genes and the abnormal regulation of key signaling pathways, which decreases the effectiveness of cancer treatment $(14,15)$. Therefore, the study of new treatment methods for breast cancer is necessary and it is vital to explore the molecular mechanism of its formation, which may provide improved treatment strategies for breast cancer.

Epigenetic modifications including DNA modifications (e.g. methylation) and histone modifications (e.g. phosphorylation and methylation) and abnormalities of non-coding RNA affect cellular function and transcriptional activity (16). A number of studies have shown that cancer is often accompanied by various histone modifications, which are related to the chromatin structure and the transcriptional activity of proto-oncogene or tumor suppressor genes, affecting the development of diverse cancers (17-19). For example, DNA hypermethylation is associated with the pathogenesis of colon cancer, lung cancer and prostate cancer (20-22). 
Abdel-Hafiz and Horwitz (23) showed that the level of histone methylation is associated with the occurrence and development of metastatic breast cancer. In addition, Liu et al (24) found that the downregulation of microRNA-20a expression can accelerate the progression of ovarian cancer. Other studies have shown that signaling pathways can directly affect important components of the epigenetic machinery (25). For instance, Avanzato et al (26) suggested that the expression of phosphorylated (p-) Akt in breast cancer tissues is significantly higher than that in the paracancerous tissues. In addition, and the PI3K/Akt pathway can positively regulates the pro-apoptotic protein BAD (27). Furthermore, Liu et al (28) revealed that the protein bifunctional arginine demethylase and lysyl-hydroxylase JMJD6 (JMJD6) promoted the development of TNBC cells by phosphorylating the histone H2AX (H2A.X) at the Tyr39 (Y39) site, which regulates autophagy genes in order to stimulate autophagy flux. In addition, the increase of autophagy flux can inhibit cell proliferation in the middle and late stages of breast cancer (28).

H2A.X plays an important role in regulating the repair of double stranded DNA breaks (29). The phosphorylation of H2A.X at Ser139 (S139) binds well with each double stranded break and is considered the most sensitive marker for examining the level of DNA damage and the subsequent repair of DNA lesions (30). In cancer cells, when the DNA repair mechanisms are dysfunctional, cells become dependent on the remaining pathways, including the PI3K/Akt and $\mathrm{ATM} / \gamma \mathrm{H} 2 \mathrm{AX}$ pathways and this renders them more vulnerable to therapies that target these specific pathways (31). The loss of H2A.X in a human non-tumorigenic breast cell line leads to the activation of epithelial-mesenchymal transition (EMT), thus enhancing the ability of migration and invasion of breast cancer cells (32). Ribosomal S6 kinase 2 (RSK2), an important regulator of cell survival, transcription, growth and proliferation, is able to phosphorylate H2A.X at S139 and Ser16 (S16) to delay the process of breast cancer (33). RSK2 is known for mediating the growth of osteosarcoma cells through regulating the Akt/mTOR signaling pathway (34). In acid-tolerable malignant mesothelioma, the phosphorylation of H2A.X is a biomarker of DNA damage, and the Akt can negatively regulate the phosphorylation of H2A.X (35). We occasionally found $\mathrm{p}$-Akt can negatively regulate the phosphorylation of H2A.X in breast cancer cells, however, at present, an interaction between Akt and H2A.X has not been reported in breast cancer, and thus, the aim of the present study was to explore this connection.

\section{Materials and methods}

Cells and animals. Human breast cancer cell lines MDA-MB-231 and MCF-7, HGC-27, HeLa cell lines were purchased from the Cell Bank of Type Culture Collection of the Chinese Academy of Sciences (Shanghai, China). The human breast cancer cell line MDA-MB-157 was obtained from the ATCC Global Bioresource Center. Cells were cultured in complete Dulbecco's modified Eagle medium (DMEM) supplemented with $0.1 \mathrm{mg} / \mathrm{ml}$ streptomycin and $100 \mathrm{U} / \mathrm{ml}$ penicillin and $10 \%$ fetal bovine serum (FBS; all purchased from Thermo Fisher Scientific, Inc.) in a humidified incubator at $5 \% \mathrm{CO}_{2}$ at $37^{\circ} \mathrm{C}$ for 1 week.
Antibodies. The primary and secondary antibodies used in this study are as follows. The primary antibodies: Akt antibody (cat. no. 9272; dilution 1:1,000), Phospho-Akt (Ser473) (193H12) Rabbit mAb (p-Akt, cat. no. 4058; dilution 1:1,000), $\beta$-actin antibody (cat. no. 4967; dilution 1:1,000), p-glycogen synthase kinase-3 $\beta$ (p-GSK3 $\beta$; cat. no. 9336, dilution 1:1,000), Phospho-GSK-3 $\alpha / \beta$ (Ser21/9) Antibody (t-GSK3 $\beta$, cat. no. 9331, dilution 1:1,000), Phospho-RSK2(Ser227)(D53A11) RabbitmAb (p-RSK2, cat. no. 3556; dilution 1:1,000), RSK2 (D21B2) $\mathrm{XP}^{\circledR}$ Rabbit mAb (cat. no. 5528; dilution 1:1,000) were purchased from Cell Signaling Technology, Inc., and anti-histone H2A.X antibody (cat. no. ab229914; dilution 1:1,000), anti-HA-tag antibody (cat. no. ab9110; dilution 1:1,0000), anti-Myc-tag [9E10] (cat. no. ab32; dilution 1:1,000), anti-histone H3 (acetyl K18) antibody (H2A.X S16ph; cat. no. ab1191; dilution 1:1,000), anti-DDDDK-tag (Binds to FLAG $^{\circledR}$ tag sequence) antibody (Flag-tag, cat. no. ab205606; dilution 1:50,000) and anti-GAPDH antibody (cat. no. ab9485; dilution 1:2,500) were purchased from Abcam. All primary antibodies were from Rabbit. The secondary antibodies: Goat Anti-Rabbit IgG H\&L (HRP) (cat. no. ab205718; dilution 1:5,000).

Western blotting. Cells were lysed using RIPA buffer (50 mM Tris, $\mathrm{pH} \mathrm{7.4,0.5 \%} \mathrm{sodium} \mathrm{deoxycholate,} 1 \%$ NP-40, $0.5 \%$ sodium deoxycholate and $150 \mathrm{mM} \mathrm{NaCl}$ ), and the protein concentration was determined using the bicinchoninic acid assay (BCA) method. Briefly, $200 \mu \mathrm{l}$ of the BCA working solution and $20 \mu \mathrm{l}$ of diluted sample protein were added per well into 96-well plates and the absorbance was measured at $526 \mathrm{~nm}$ after incubation at $37^{\circ} \mathrm{C}$ for $30 \mathrm{~min}$. Protein concentration was calculated in relation to the standard curve. Protein samples $(50 \mu \mathrm{g})$ were then separated using 10\% SDS-PAGE and transferred to PVDF membranes, followed by blocking at $25^{\circ} \mathrm{C}$ for $1 \mathrm{~h}$ in 5\% non-fat milk powder. Membranes were then incubated at $4^{\circ} \mathrm{C}$ overnight with primary antibodies. The membranes were then washed with TBS-Tween buffer to remove the free protein and incubated with anti-goat and anti-rabbit IgG H\&L (HRP) (cat. no. ab205718; dilution 1:5,000; Abcam) secondary antibodies at $25^{\circ} \mathrm{C}$ for $1 \mathrm{~h}$. The protein bands were visualized using the ECL Western blotting kit (cat. no. WP20005; Thermo Fisher Scientific, Inc.), and the bands were exposed to autoradiography film. $\beta$-actin was used as the loading control. Each experiment was repeated three times.

Cell transfection and treatment. Akt siRNA (si-Akt), RSK2 siRNA (si-RSK2), negative control siRNA (si-NC), RSK2 ${ }^{\text {S19A }}$ (Ser19 site of RSK2 was replaced by Ala) plasmid and RSK2 ${ }^{\text {S19E }}$ (Ser19 site of RSK2 was replaced by S19E) plasmid were purchased and constructed by Hanbio Biotechnology Co., Ltd. The sequences of siRNA: si-Akt, 5'-CUGACCAAG AUGACAGCAU-3' (sense), 5'-AUGCUGUCAUCUUGGUCA G-3' (antisense); si-RSK2, 5'-A GUUUACUGAUGGAUA UGAAGUAAA-3' (sense), 5'-AGAAGAAGAUGUCAAAUU CUACUUG-3' (antisense); si-NC, 5'-UUCUCCGAACGU GUCACGUTT-3' (sense), 5'-ACGUGACACGUUCGGAGA ATT-3' (antisense). DN-Akt (dominant negative Akt) and CA-Akt (constitutively activated Akt) were purchased from (Addgene, Inc.).MBA-MD-231 cells $\left(10^{6}\right.$ cells $\left./ \mathrm{ml}, 50 \mu \mathrm{l} / \mathrm{well}\right)$ were cultured in the 6-well plates with complete DMEM for $24 \mathrm{~h}$, before being transfected with the plasmids $(1 \mu \mathrm{g} / \mathrm{ml})$ 
include the control empty vector pEGFP-N1, and the generated plasmids DN-Akt, CA-Akt, RSK2 ${ }^{\text {S19A }}$ and RSK2 ${ }^{\text {S19E }}$. In addition, si-Akt, si-RSK2 and the si-NCwere also transfected. Transfections were performed using Lipofectamine 3,000 (Invitrogen; Thermo Fisher Scientific, Inc.). After $48 \mathrm{~h}$ of transfection, the transfection efficiency was determined by western blotting. As presented in Fig. S1, the transfection efficiency was high. When needed cells were stimulated with insulin-like growth factor (IGF) $15 \mathrm{ng} / \mathrm{ml}$ for $30 \mathrm{~min}$ or treated with the PI3K-Akt inhibitor LY294002 $16 \mu \mathrm{M}$ for $24 \mathrm{~h}$.

Peptide competition assay. A polyclonal antibody was generated in-house to specifically recognize an RSK2 peptide that harbored the phosphorylated S19 (anti-RSK2-S19ph antibody). The specificity of the anti-RSK2-S19ph antibody was examined by peptide competition assay. The synthesized phospho-RSK2 and non-phospho-RSK2 peptides were purchased from Medical \& Biological Laboratories (Beijing, China). Firstly, $10 \mu \mathrm{M}$ anti-RSK2-S19ph antibody was pre-incubated with phospho-RSK2 or non-phospho-RSK2 peptide for $20 \mathrm{~min}$ at $30^{\circ} \mathrm{C}$. Then, the total protein was extracted from MDA-MB-231 cells using 1x SDS buffer, and boiled at $95^{\circ} \mathrm{C}$ for $10 \mathrm{~min}$ to inactivate the protein. Next, the total protein was separated on 15\% SDS-PAGE, and transferred to PVDF membranes. Then the membranes were incubated with anti-RSK2-S19ph antibody $(1: 1,000)$ pre-treated with phospho-RSK2 or non-phospho-RSK2 peptides for $1 \mathrm{~h}$ at $30^{\circ} \mathrm{C}$ for the detection of p-RSK2. The membranes were also incubated anti-RSK2 antibody $(1: 1,000)$ with same condition for the detection of RSK2.

MTT assay. MTT assay was used to detect the viability of MDA-MB-231 cells. The MDA-MB-231 cells were cultured in MDEM with penicillin-streptomycin and FBS for 7 days at $37^{\circ} \mathrm{C}$. Then, the cells were seeded into 96 -well plates $\left(5 \times 10^{3}\right.$ cells/well $)$ with complete DMEM $(100 \mu 1$ per well). Next, the cells were transfected with WT-/MUT (S19A and S19E)-RSK2 plasmids, and the blank vector as the negative control. A total of $20 \mu 1$ of a $5 \mathrm{mg} / \mathrm{ml}$ MTT solution (Sigma-Aldrich, Merck KGaA) was added to each well after the cells were cultured for 1, 2 and 3 days, and the plate was incubated for $4 \mathrm{~h}$ at $37^{\circ} \mathrm{C}$. Then, the MTT was discarded, and DMSO (150 $\mu \mathrm{l} /$ well) was added to each well. The plate was incubated for $10 \mathrm{~min}$ and the absorbance values were measured at $570 \mathrm{~nm}$ using a microplate reader.

Soft agar colony formation assay. First of all, we carried out a pre-experiment of colony formation assay to measure the cell vitality by using acid phosphatase method to detect the cellular ability of survival and proliferation. Then, a cell suspension (MDA-MB-231 cells with DMEM, FBS and penicillin-streptomycin) of 1,000 living cells/m and were added to $3 \%(\mathrm{w} / \mathrm{v})$ melted agar. Then, the cell-agar suspensions $(1 \mathrm{ml} /$ well $)$ were added into 6-well plates and after solidification, cells were maintained at $37^{\circ} \mathrm{C}$. After 14 days, cells were fixed with $4 \%$ paraformaldehyde and stained with $1 \%$ crystal violet and the colonies were counted manually.

Transwell migration assay. Cell migration was assayed using a Transwell chamber $(8 \mu \mathrm{m}, 12$ wells $)$. A total of $1 \times 10^{4}$ cells in serum-free DMEM were transferred to the upper compartment of the well inserts and the cells were cultured for $24 \mathrm{~h}$ at $37^{\circ} \mathrm{C}$. Meanwhile, the lower compartment was filled with complete DMEM (10\% FBS). After $24 \mathrm{~h}$, the cells on the top surface of the membrane were wiped off softly with a cotton swab and the cells that migrated to the bottom of the membrane were fixed with methanol and were stained with 5\% crystal violet for $10 \mathrm{~min}$ at room temperature and were visualized using a Leica DC 300F microscope (magnification, x400).

Kinase activity assay. The kinase activity of RSK2 was tested by measuring the level of H2A phosphorylation after stimulation with RSK2. The assay mixture included the Myc-tag wild type (WT) RSK2 plasmid (addgen) or the mutant RSK2 (MUT-RSK2) plasmids (S19A and S19E), with $10 \mu \mathrm{M} \mathrm{CoA}$ (Abcam) and $10 \mu \mathrm{g} \mathrm{H} 2 \mathrm{~A}$ (Abcam), which were incubated with the kinase assay buffer (Thermo Fisher Scientific, Inc.) for $30 \mathrm{~min}$ at $30^{\circ} \mathrm{C}$. The kinase activity of hemagglutinin (HA)-tagged Akt (HA-Akt) phosphorylating Myc-tagged RSK2 (Myc-RSK2) was assayed by western blotting by measuring the phosphorylated $\mathrm{H} 2 \mathrm{~A}$ in the presence of $\mathrm{H} 2 \mathrm{~A}$ and acetyl-CoA. In addition, the protein tags, including Myc and HA were attached to carrier and used to detect the target protein more conveniently.

Chromatin immunoprecipitation (ChIP). A total of $3 \times 10^{6}$ cells $/ \mathrm{ml}$ were crosslinked in $1 \%$ formaldehyde for $10 \mathrm{~min}$ at $25^{\circ} \mathrm{C}$, followed by washing with ice-cold PBS for 3 times and cell lysis with SDS lysis buffer (Upstate Biotechnology, Inc.). The lysates were then sonicated to shear the DNA into 200-800 bp fragments and centrifuged at $12,000 \mathrm{x}$ g for 5 min at $4^{\circ} \mathrm{C}$. The supernatant was diluted with ChIP DB (1\% Triton X-100; 1.2 mM EDTA; 16.7 mM Tris-HCL, pH 0.8; $167 \mathrm{mM} \mathrm{NaCl} ; 0.1 \mathrm{mM}$ PMSF) and was cultured overnight with the $\mathrm{A} / \mathrm{G}$ agarose beads (Cell Signaling Technology, Inc.) and primary antibody against RSK2, H2A.X and $\beta$-actin at $4^{\circ} \mathrm{C}$. The normal anti-Rabbit immunoglobulin $\mathrm{G}$ (IgG) antibody served as the control. The beads were washed for 5 min with low-salt $(150 \mathrm{mM} \mathrm{NaCl} ; 0.1 \%$ SDS; $1 \%$ Triton X-100; $2 \mathrm{mM}$ EDTA; $20 \mathrm{mM}$ Tris-HCL, pH 0.8) high-salt $(500 \mathrm{mM} \mathrm{NaCl}$; $0.1 \%$ SDS; $1 \%$ Triton X-100; 2 mM EDTA; 20 mM Tris-HCl, $\mathrm{pH} 0.8$ ) and $\mathrm{LiCl}$ buffers at $4{ }^{\circ} \mathrm{C}$ and were finally washed with $1 \mathrm{X}$ Tris-EDTA at $25^{\circ} \mathrm{C}$ for $2 \mathrm{~min}$. The DNA was eluted from the beads by adding $1 \%$ SDS and $\mathrm{NaCl}$ was added to the eluant for $7 \mathrm{~h}$ at $65^{\circ} \mathrm{C}$ to reverse the crosslinks. Subsequently, the eluted DNA was precipitated by ethanol at $-20^{\circ} \mathrm{C}$, following by treatment with $20 \mu \mathrm{g}$ proteinase $\mathrm{K}$ to digest proteins attached to DNA. DNA was purified utilizing the QIAquick PCR Purification Columns (Qiagen China Co., Ltd.). Finally, the purified DNA was analyzed by RT-qPCR.

Co-immunoprecipitation analysis. MDA-MB-231 cells were washed three times with ice-cold PBS and lysed in RIPA lysis buffer [50 mM Tris (pH 7.4), $150 \mathrm{mM} \mathrm{NaCl}, 1 \% \mathrm{NP}-40$, $0.5 \%$ sodium deoxycholate] for $30 \mathrm{~min}$ on ice. After the lysates were centrifuged at $4^{\circ} \mathrm{C}$ for $30 \mathrm{~min}$ at $12,000 \mathrm{xg}$, the supernatant was incubated with the primary antibodies: Anti-Akt antibody (cat. no. 9272; dilution 1:1,000; Cell Signaling Technology, Inc.) and anti-RSK2 antibody (cat. no. 5528; dilution 1:1,000; Cell Signaling Technology, Inc.) overnight at $4^{\circ} \mathrm{C}$. The normal anti-Rabbit IgG antibody (cat. no. 2729; dilution 1:1,000, Cell 
Table I. Primer sequences used for quantitative PCR.

\begin{tabular}{lll}
\hline Gene & \multicolumn{1}{c}{ Forward $\left(5^{\prime}-3^{\prime}\right)$} & \\
\hline RSK2 & TCCGACTTAAATGAAAGGAG & Reverse $\left(5^{\prime}-3^{\prime}\right)$ \\
CDKN2A & GAAGAAAGAGGAGGGGTTGG & GCTCAGCATTGTAGGTGAC \\
PUMA & GCCAGATTTGTGAGACAAGAGG & GAAGAAAGAGGAGGGGTTGG \\
Dram 1 & GCGCGCTCCGGAAATCCCCCGGGAG & CAGGCACCTAATTGGCTC \\
PTEN & CCGAAAGGTTTTGCTACCATTCT & AAAATTATTTCCTTTCTGAGCATTCC \\
ING3 & ACCTGAGTGGAGGGAAGAGC & CTGGTTTGCCAACTGAACCT \\
PSAT-1 & CGGAATTCCGATGGACGCCCCCA & GGAAGATCTCTCATAGCTGATGCATCTCCA \\
Bax & TGCTTCAGGGTTTCATCCAGG & TGGCAAAGTAGAAAAGGGCGA \\
RTK6 & CGTACGAGGTAAACAGGAG & AGCTTGTTCTCCTCGCTGTA \\
GAPDH & TCGACAGTCAGCCGCATCTTCTTT & GCCCAATACGACCAAATCCGTTGA \\
-actin & TCAGGTCATCACTATCGGCAAT & AAAGAAAGGGTGTAAAACGCA \\
\hline
\end{tabular}

Signaling Technology, Inc.) served as the negative control, and the whole lysates as the positive control. On the following day, A/G agarose beads (Cell Signaling Technology, Inc.) were added to the lysates and incubated for a further $3 \mathrm{~h}$, after which the beads were washed with PBS and collected by centrifugation for $5 \mathrm{~min}$ at $3,000 \mathrm{x} \mathrm{g}$ at $4^{\circ} \mathrm{C}$. The proteins were released by boiling the samples and were analyzed by western blotting on a $15 \%$ SDS-PAGE.

Reverse transcription-quantitative $(R T-q) P C R$. The total RNA of RSK2 and the target genes of Akt like PSAT-1 were extracted and purified using TRIzol reagent (Invitrogen; Thermo Fisher Scientific, Inc.), according to the manufacturer's instructions. Next, $5 \mu \mathrm{g}$ total RNA was applied to synthesize cDNA using the First Strand cDNA Synthesis kit (Thermo Fisher Scientific, Inc.), according to the manufacturer's instructions. Then, the mixture system including SYBR Green qPCR Master Mix (500 nM), cDNA templates (50 ng) and primers (500 nM) were applied to Real-time qPCR to detect the expression of RSK2 and PSAT-1, according to standard methods $\left(95^{\circ} \mathrm{C}, 3 \mathrm{~min}\right.$; $95^{\circ} \mathrm{C}, 30 \mathrm{sec}, 30$ circles; $55^{\circ} \mathrm{C}, 30 \mathrm{sec}$, and $72^{\circ} \mathrm{C}, 60 \mathrm{sec}$ ). Finally, the PCR products was electrophoresed with $1.5 \%$ agarose gel, and the electrophoretic bands were observed. The relative expression was calculated by $2^{-\Delta \Delta \mathrm{Cq}}$ method (36). GAPDH were applied to as an internal control of the target gene of Akt, and the $\beta$-actin as the control of RSK2. The primer sequences used for qPCR are listed in Table I.

Statistical analysis. All experiments were performed in triplicate and data are presented as the mean \pm standard deviation. Statistical analysis between two groups was calculated using unpaired Student's t-test, and the comparison among multiple groups was evaluated with ANOVA with Sidak's multiple comparisons test. The statistical graphs were drawn using GraphPad Prism (version 7.0; GraphPad Software, Inc.). $\mathrm{P}<0.05$ was considered to indicate a statistically significant difference.

\section{Results}

Akt inversely regulates H2A.X S16ph. MDA-MB-231 was selected as the main experimental cell line as it has a higher ability of invasion and migration compared with the other breast cancer cell lines (37). Western blot results showed that breast cancer cells with high levels of p-Akt generally had lower levels of H2A.X S16ph (Fig. 1A). This phenomenon prompted the investigation on whether H2A.X S16 phosphorylation was affected by Akt. Indeed, when the MDA-MB-231 cells were stimulated with IGF to increase the phosphorylation of Akt, a decrease in H2A.X S16ph was observed, and this effect was reversed after the introduction of the PI3K-Akt inhibitor LY294002 (Fig. 1B). Likewise, when the MDA-MB-231 cells were transfected with DN-Akt (Fig. 1C and S1A) or when the expression of Akt was knocked down by siRNA (Fig. 1D) the phosphorylation of H2A.X S16 also increased. As presented in Fig. 1C, GSK3 $\beta$ was a control of p-Akt as it can be phosphorylated by Akt (38). Furthermore, the phosphorylation of H2A.X S16 was negatively associated with the activity of Akt over time (Fig. 1E).

Akt interacts with and phosphorylates RSK2 on Ser19 (S19). To examine how the phosphorylation of H2A.X S16 was regulated by Akt signaling, the activity of the RSK2 enzyme that regulates H2A.X S16ph (33) was assessed. No change was observed after IGF was added (Fig. S2). Thus, Akt was examined to understand if it can regulate RSK2 activity and therefore affect the phosphorylation of H2A.X S16. Co-immunoprecipitation experiments were performed to confirm the interaction between RSK2 and Akt. Results showed that Myc-RSK2 and HA-Akt could be detected in the presence of each other, when CA-Akt was expressed but not DN-Akt (Fig. 2A). Besides, the association between the endogenous Akt and RSK2 was reduced after treatment with LY294002 (Fig. 2B). Thus, the results suggested that Akt and RSK2 interacted with each other in vitro.

Subsequently, a kinase assay was performed using RSK2 mutants of possible phosphorylation sites to verify whether the phosphorylation site was S19. The result showed that when the S19 site of RSK2 was replaced by an Ala or Glu (S19A and S19E, respectively) or by glutathione S-transferase (GST as a negative control), RSK2 was not phosphorylated by Akt (Fig. 2C). Next, a polyclonal antibody was generated in-house that specifically recognized an RSK2 peptide that harbored the 


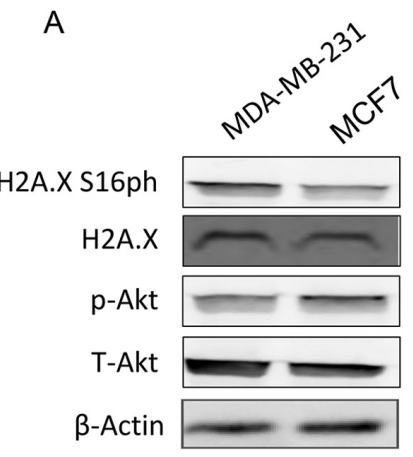

D

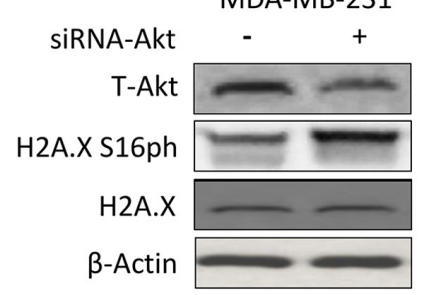

B
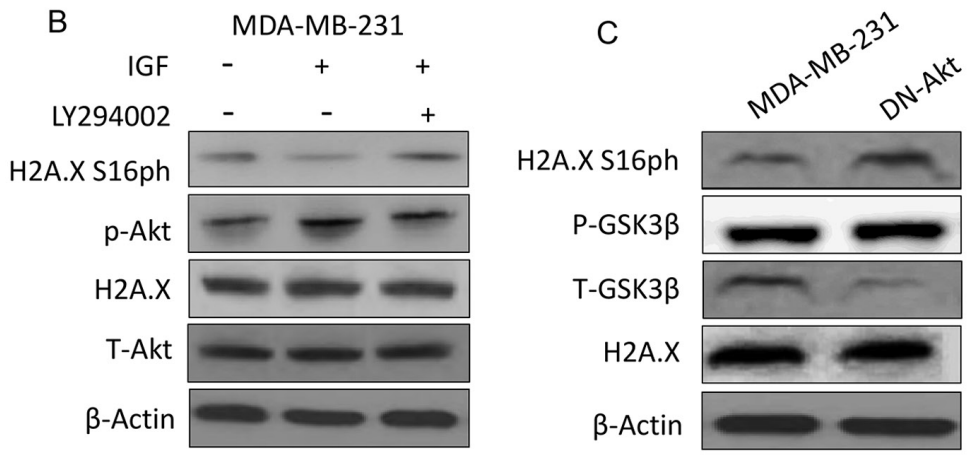

E

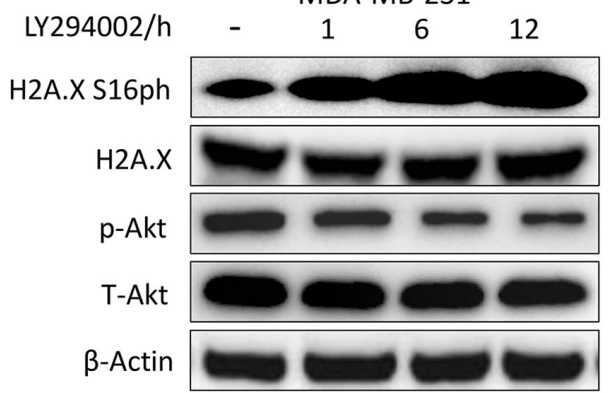

Figure 1. Akt inversely regulates H2A.X S16ph. (A) The phosphorylation levels of H2A.X S16 and Akt were detected by western blotting in the MDA-MB-231 and MCF7 cell lines. (B) H2A.X S16ph and Akt were detected by western blotting after cell treatment with IGF and/or the PI3K-Akt inhibitor LY294002. (C) H2A.X S16ph in the MDA-MB-231 cell line transfected with or without DN-Akt was assayed by immunoblotting. GSK3 $\beta$ is related to the activation of Akt and is considered a marker to judge the degree of Akt activation. (D) Western blot analysis detecting H2A.X S16ph in the MDA-MB-231 cells transfected with or without an siRNA targeting Akt for $24 \mathrm{~h}$. (E) Immunoblot analysis of H2A.X S16ph and Akt after treatment with LY294002 for 1, 6 and 12 h. H2A.X, histone H2AX; H2A.X S16ph, H2A.X phosphorylated at the Ser16 site; p-, phosphorylated; IGF, insulin-like growth factor; DN, dominant negative; GSK3 $\beta$, glycogen synthase kinase- $3 \beta$; t, total.
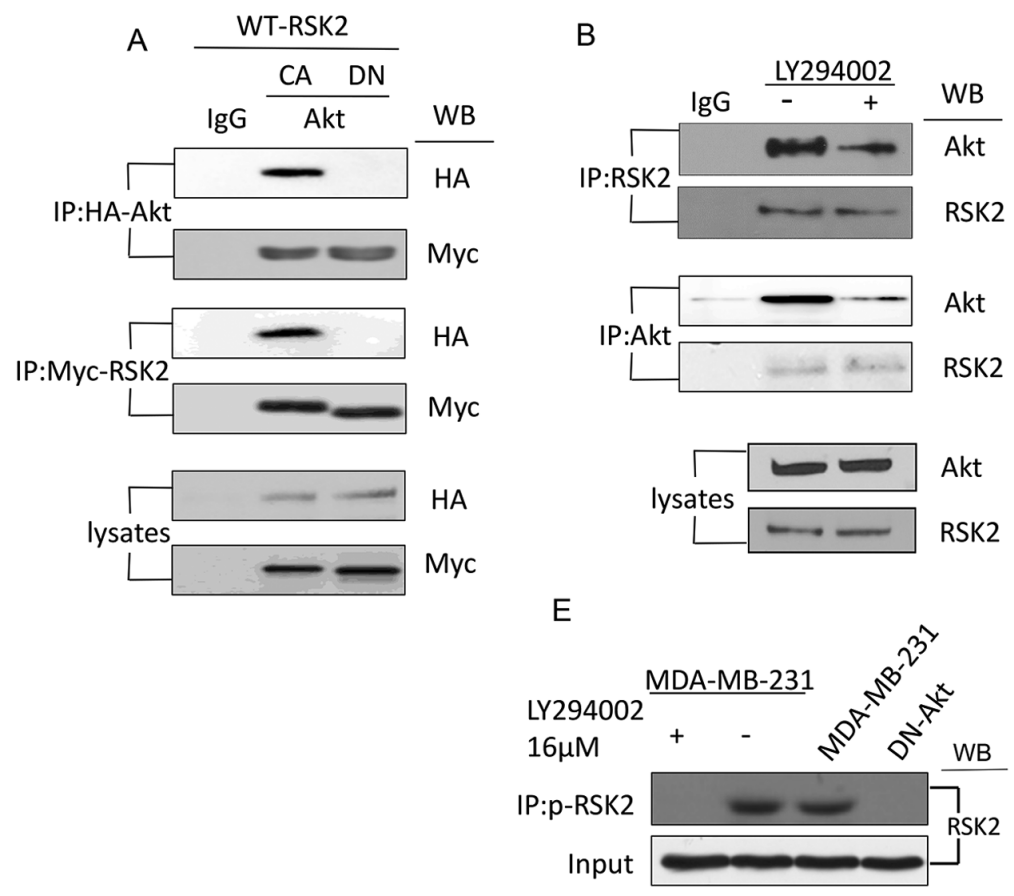

B
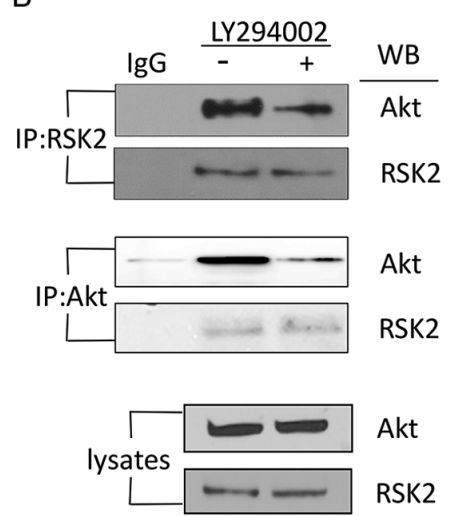

C
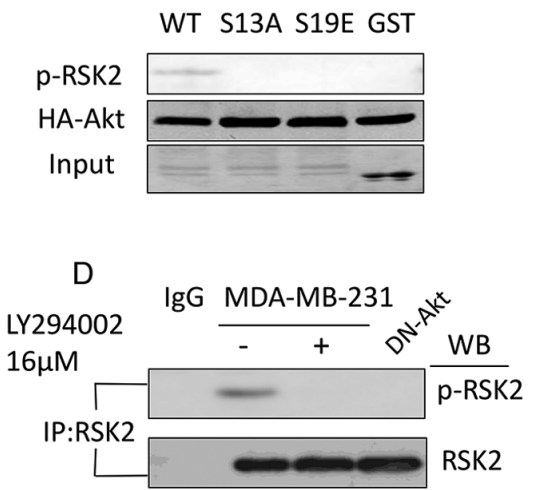

$\mathrm{F}$

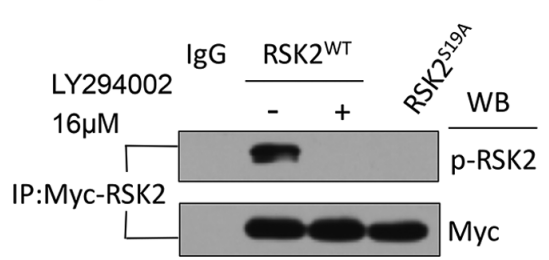

Figure 2. Akt interacts with and phosphorylates RSK2 at S19. (A) Co-IP was used to analyze the lysates from the MDA-MB-231 cells transfected with the CA-Akt and DN-Akt plasmids using antibodies targeting HA and Myc. (B) Co-IP was used to detect the interaction of endogenous RSK2 and Akt in the MDA-MB-231 cells with or without the PI3K-Akt inhibitor LY294002. (C) A western blot was used to observe the phosphorylation of RSK2 in the MDA-MB-231 cells with WT- or mutant-RSK2 at the S19 site. (D) Endogenous RSK2 was immunoprecipitated using a RSK2-antibody or a p-RSK2 antibody in the MDA-MB-231 cells treated with or without LY294002 or the MDA-MB-231 cells transfected with DN-Akt. (E) The antibody targeting p-RSK2 was used to immunoprecipitate the phosphorylated endogenous RSK2, and the antibody targeting RSK2 was used for the western blotting assay. (F) An IP was performed to assess RSK2 in the cells transfected with the WT-RSK2 (in the presence or absence of LY294002) or RSK2 $2^{\text {S19A }}$ plasmids, and the precipitates were subjected to a western blot using the antibody targeting p-RSK2. S19, Ser19; WB, western blotting; RSK2, ribosomal S6 kinase 2; RSK2 $219 \mathrm{~A}$, RSK2 Ser19Ala; CA, constitutively activated; DN, dominant negative; p-, phosphorylated; HA, hemagglutinin; IP, immunoprecipitation; IgG, immunoglobulin G. 

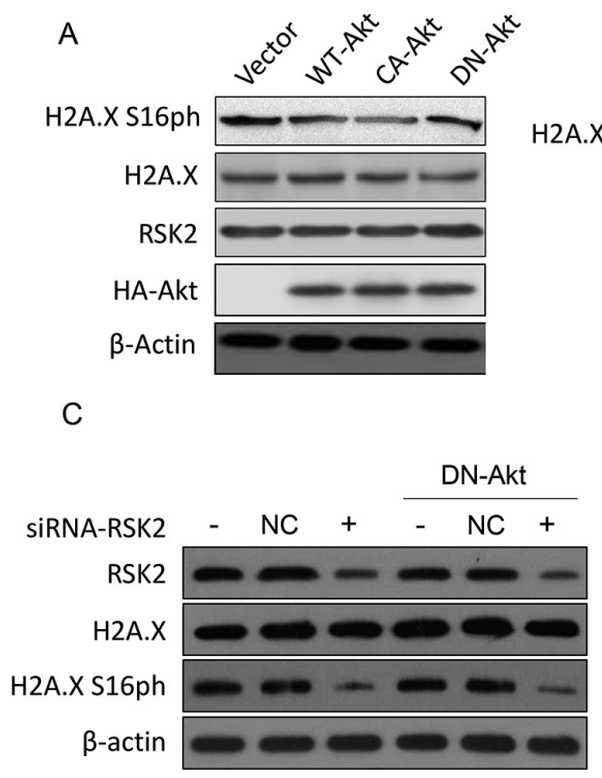

B

H2A.X S16ph
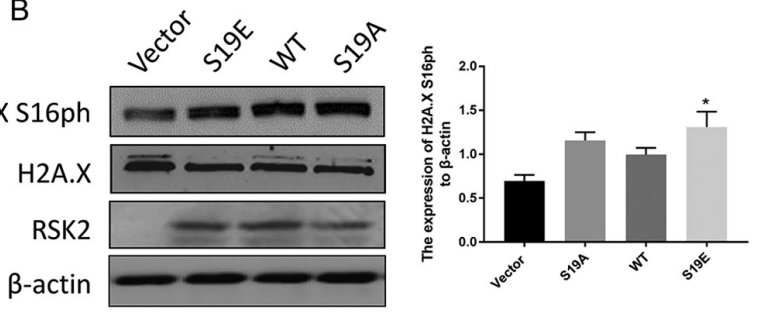

D HA-CAAkt - + - +

E

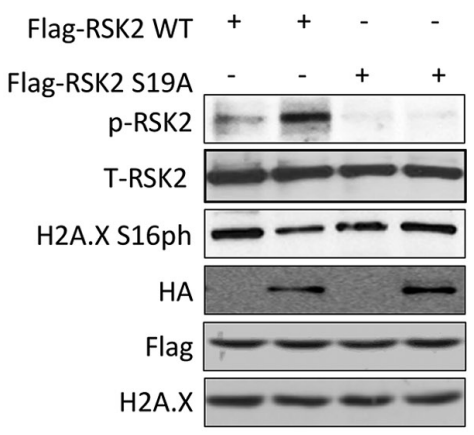

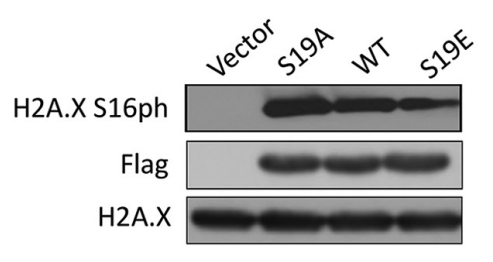

Figure 3. Akt suppresses RSK2 kinase activity. (A) MDA-MB-231 cells were transfected with WT-Akt, CA-Akt and DN-Akt plasmids, and the cell lysates were subjected to a western blot assay $48 \mathrm{~h}$ after the transfection. (B) MDA-MB-231 cells were transfected with WT-RSK2, RSK2 ${ }^{\text {S19A }}$ and RSK2 ${ }^{\text {S19E }}$ plasmids and a western blot assay was performed $48 \mathrm{~h}$ after the transfection. "P<0.05. (C) A Western blot assay was used to detect the levels of H2A.X S16ph in the MDA-MB-231 cells and the DN-Akt MDA-MB-231 cells transfected with the siRNA-RSK2 or NC. (D) WT or S19A mutant Flag-RSK2 were mixed with HA-CA Akt, which was immunoprecipitated from the untreated lysates, and these were incubated for $30 \mathrm{~min}$ in the kinase assay buffer. Then, the kinase activity was detected with the indicated antibodies. (E) After the WT-RSK2, RSK2 ${ }^{\mathrm{S} 19 \mathrm{~A}}$ and RSK2 ${ }^{\mathrm{S} 19 \mathrm{E}}$ plasmids were transfected into the MDA-MB-231 cells, the level of H2A.X S16ph in vitro was detected by co-immunoprecipitation with a Flag antibody. Then, the kinase activity was assayed for the indicated antibodies. The empty vectors were used as the negative control, and WT-RSK2 was used as the positive control to eliminate the interference of foreign sequences. S19A, Ser19Ala; S19E, Ser19Glu; RSK2, ribosomal S6 kinase 2; CA, constitutively activated; DN, dominant negative; HA, hemagglutinin; H2A.X, histone H2AX; H2A.X S16ph, H2A.X phosphorylated at the Ser16 site; NC, negative control; WT, wild type; t-total; p, phosphorylated.

phosphorylated S19 (anti-RSK2-S19ph antibody) to confirm that Akt phosphorylated RSK2 at S19 in vitro (Fig. S3). The association of the phosphorylation of RSK2 at S19 site and Akt was observed in multiple cell lines including the gastric cancer cell line HGC-27 using the specially designed antibody (Fig. S4).

Subsequently, immunoprecipitation and immunoblotting were used to investigate whether the phosphorylation of RSK2 at S19 was regulated by Akt using endogenous RSK2 from MDA-MB-231 cells transfected with DN-Akt or treated with LY294002 (Fig. 2D). The result showed that the RSK2 in the MDA-MB-231 cells was phosphorylated in the presence of LY194002 (inhibitor of Akt), but the RSK2 in cells transfected with DN-Akt or in those treated with LY194002 was not phosphorylated (Fig. 2D). In addition, when performing the immunoprecipitation using an antibody against p-RSK2, and western blot using an antibody against RSK2, results showed that the levels of p-RSK2 were reduced when Akt activity was blocked (Fig. 2E). Additionally, when the cells were transfected with the WT- or S19A-RSK2 plasmid, a similar result was observed (Fig. 2F). Altogether these experiments suggested that Akt phosphorylated RSK2 at S19.

Akt suppresses RSK2 kinase activity. To confirm whether the Akt-mediated phosphorylation of RSK2 inhibit the phosphorylation of H2A.X S16, a western blot was performed. The data revealed that $\mathrm{CA}-\mathrm{Akt}$ decreased the phosphorylation of H2A.X S16 but DN-Akt maintained the phosphorylation of
H2A.X S16 (Fig. 3A). In addition, the level of H2A.X S16ph in the cells transfected with RSK2 ${ }^{\mathrm{S} 19 \mathrm{~A}}$ was slightly higher than the H2A.X S16ph in the cells transfected with RSK2 $2^{\mathrm{S} 19 \mathrm{E}}$ (mimicking the phosphorylated state of RSK2) (Fig. 3B). In addition, the levels of H2A.X S16ph decreased when RSK2 was knocked down using siRNA, and this effect was not reversed by DN-Akt (Fig. 3C). In conclusion, p-RSK2, mediated by Akt, inhibited the phosphorylation of H2A.X S16.

In order to further prove that the phosphorylation of RSK2 at $\mathrm{S} 19$ by Akt affected the kinase activity of RSK2, in vitro kinase experiments were carried out with WT-RSK2, RSK2 $2^{\text {S19A }}$ and CA-Akt obtained by immunoprecipitation. An increase in the phosphorylation levels of RSK2 and a decrease in RSK2 kinase activity (reflected by a decrease in H2A.X S16ph) were observed for the WT-RSK2 but not the RSK2 ${ }^{\text {S19A }}$ mutant (Fig. 3D). Flag-tag was used to locate the protein (Fig. 3D). To support this discovery, another kinase activity assay was performed with RSK2 expressed in vitro, where the results showed that H2A.X S16 was phosphorylated by the transfection of WT-RSK2 when compared to the empty vector control, and this phosphorylation was enhanced by the expression of RSK $2^{\mathrm{S} 19 \mathrm{~A}}$ and was weakened by the expression of RSK2 $2^{\mathrm{S} 19 \mathrm{E}}$ (Fig. 3E). These data suggested that the phosphorylation of RSK2 at S19 regulated by Akt is responsible for regulating the activity of the RSK2 kinase.

Akt-mediated phosphorylation of RSK2 changes substrate affinity. Co-immunoprecipitation assays were used to confirm 

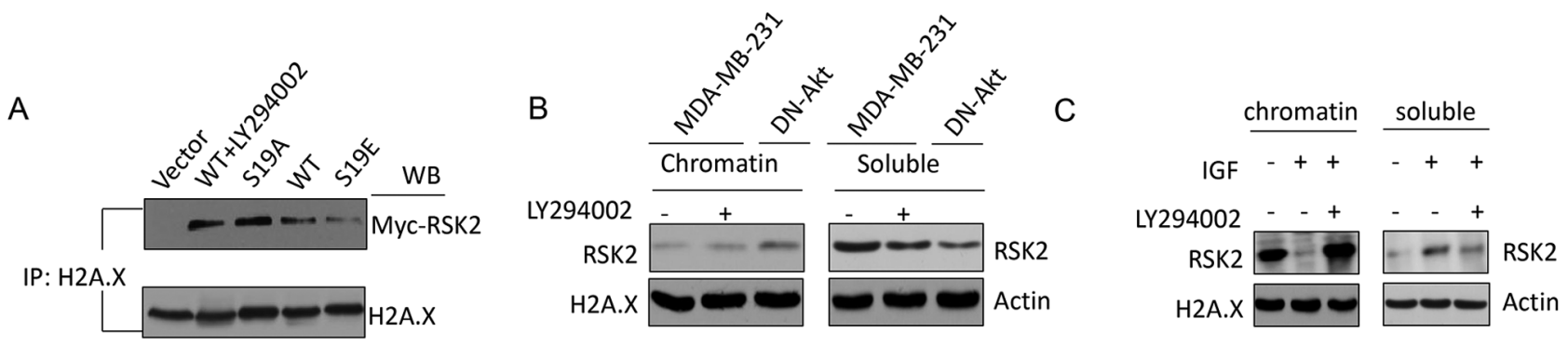

D

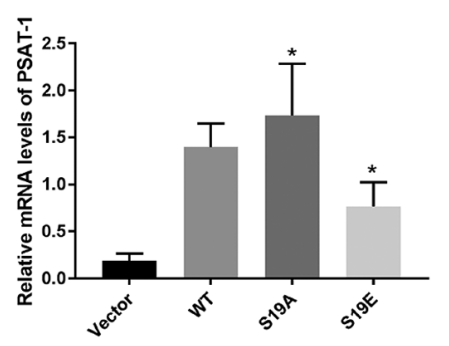

E

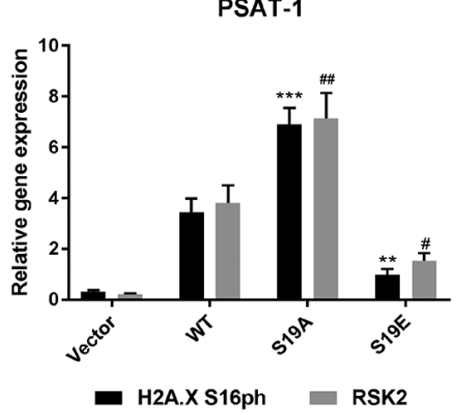

F

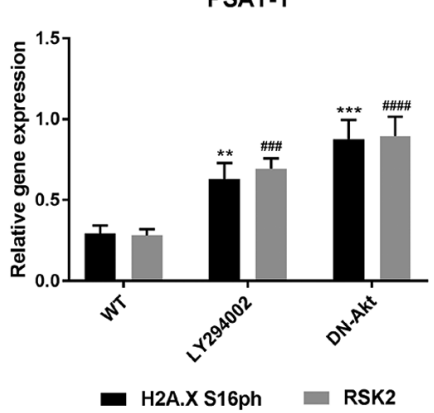

Figure 4. Akt-mediated phosphorylation of RSK2 changes substrate affinity. (A) The endogenous histone H2A.X was determined by co-IP in MDA-MB-231 cells transfected with WT-RSK2 (in the presence or absence of the PI3K-Akt inhibitor LY294002) or MUT-RSK2 (S19A and S19E) plasmids. (B-C) Western blot of the endogenous RSK2 in the c and s fractions from the (B) MDA-MB-231 cells (in the presence or absence of LY294002) and the DN-Akt transfected MDA-MB-231 cells, and (C) the MDA-MB-231 cells treated with IGF or a combination of IGF and LY294002. (D) The relative PSAT-1 mRNA expression levels of in the MDA-MB-231 cells transfected with vector, WT- or MUT-RSK2 (S19A and S19E) plasmids were measured by RT-qPCR. *P<0.05 vs. WT. (E-F) The expression of PSAT-1 in the (E) HeLa cells transfected with the WT- or MUT-RSK2 (S19A and S19E) and (F) MDA-MB-231 cells (in the presence or absence of LY294002) and the DN-Akt transfected MDA-MB-231 cells was quantified via RT-qPCR analysis. ${ }^{* *} \mathrm{P}<0.01 ;{ }^{* * *} \mathrm{P}<0.001$ vs. H2A.X S16ph. ${ }^{\#} \mathrm{P}<0.05$;

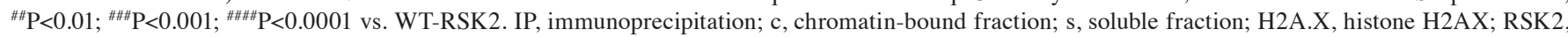
ribosomal S6 kinase 2; DN, dominant negative; IP, immunoprecipitation; WB, western blotting; PSAT-1, phosphoserine aminotransferase 1; IGF, insulin-like growth factor; MUT-RSK2, mutant-RSK2; S19A, Ser19Ala; S19E, Ser19Glu; RT-qPCR, reverse transcription-quantitative PCR; WT, wild type.

whether the phosphorylation of RSK2 affects its affinity to histone H2A. The association of H2A with RSK2 ${ }^{\text {S19A }}$ was greater than H2A with RSK2 ${ }^{\text {S19E }}$ and WT-RSK2 + LY294002 (Fig. 4A). Next, the binding of RSK2 with soluble protein (S) and insoluble (chromatin-bound) nucleoplasm (C) was evaluated by ChIP in cells for which Akt has been induced by IGF or suppressed by the transfection of DN-Akt or treatment with LY294002 inhibitor. The results demonstrated that the rate of the integration of RSK2 with the chromatin-bound was high when Akt was suppressed, but it was low when Akt was promoted (Fig. 4B-C). The results about the integration rate of RSK2 with soluble demonstrated that the integration rate was high when Akt was overexpressed; however, it was low when Akt was inhibited (Fig. 4B and C).

Moreover, to clarify whether p-RSK2 had a positive effect on neoplasia, the influence of p-RSK2 on target genes from the Akt pathway was assessed with MDA-MB-231 cells. The altered transcription of these genes was confirmed by RT-qPCR (Fig. S5). Certain genes that are affected by RSK2 have been reported to be associated with tumor progression, such as phosphoserine aminotransferase 1 (PSAT-1) that is known as an oncogene from an erythropoietin-producing hepatoma cell line (39), and its expression was promoted by $\mathrm{RSK} 2^{\mathrm{S} 19 \mathrm{~A}}$ (RSK2 $2^{\mathrm{S} 19 \mathrm{~A}}$ could not be phosphorylated) and inhibited by $\mathrm{RSK} 2^{\mathrm{S} 19 \mathrm{E}}$ when compared with the WT control (removes the influence of exogenous sequence) (Fig. 4D). PCR analysis demonstrated that H2A.X S16ph was highly expressed in the promoter of PSAT-1 of the cells transfected with RSK2 ${ }^{\text {S19A }}$ (Fig. 4E). In addition, high levels of H2A.X S16ph were observed in the promoter of PSAT-1 of the cells transfected with DN-Akt (Fig. 4F). All experimental results indicated that p-RSK2 may inhibit the phosphorylation of H2A.X and promote the occurrence and development of cancer.

Phosphorylation of RSK2 at S19 by Akt enhances its oncogenic activities. To further demonstrate that the phosphorylation of RSK2 mediated by Akt induced oncogenic activity, MTT, soft agar colony formation and Transwell migration assays were performed in the MDA-MB-231 cells transfected with the WT-RSK2 or MUT-RSK2 (S19A and S19E). The experimental results showed that RSK2 ${ }^{\mathrm{S} 19 \mathrm{E}}$ and WT-RSK2 promoted cell viability and migration, but RSK2 ${ }^{\mathrm{S} 19 \mathrm{~A}}$ suppressed cell survival and migration when compared with the empty vector control (Fig. 5A-C).

\section{Discussion}

In the present study, Akt was found to mediate the phosphorylation of RSK2 at the S19 site, which inhibited the phosphorylation of H2A.X at S16. In addition, it was revealed that the interaction of Akt, RSK2 and H2A.X reduced the affinity between RSK 2 and the substrate histone and also inhibited the expression of the cancer promoter, PSAT-1 to some extent, thereby promoting the viability and migration of breast cancer cells. 
A

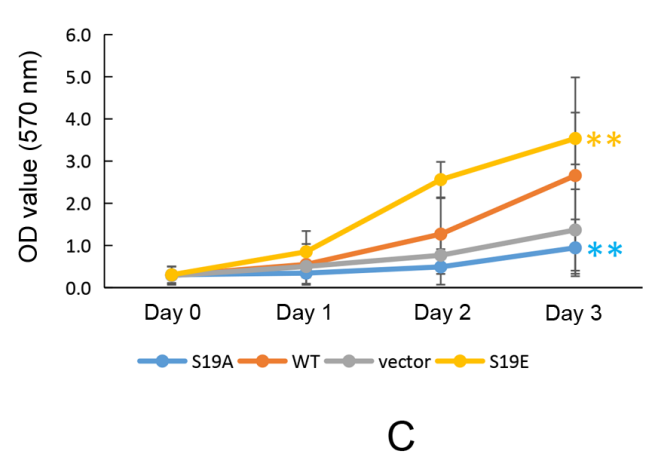

B
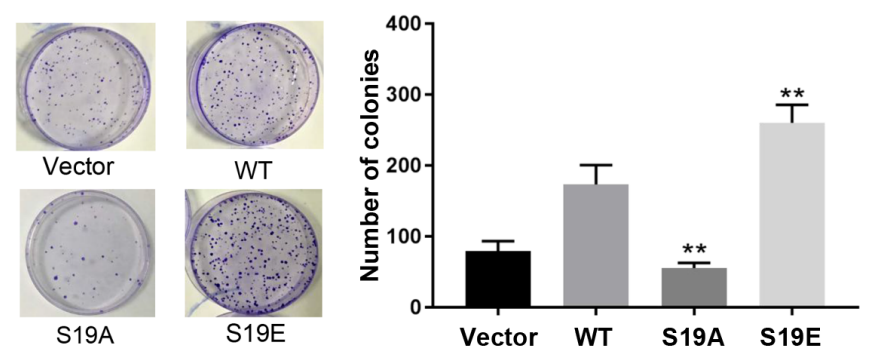

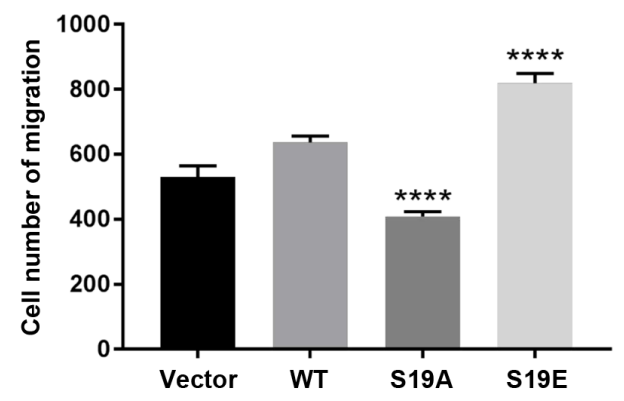

Figure 5. Phosphorylation of RSK2 at S19 by Akt enhances its oncogenic activities. (A-C) MDA-MB-231 cells were transfected with a vector, WT-RSK2 or mutant-RSK2 plasmids (S19A and S19E). (A) MTT assay was used to detect cell viability. (B) The ability of cells to proliferate as colonies was quantified by a soft agar colony formation assay. (C) The migratory ability of the cancer cells was assessed using a Transwell migration assay. ${ }^{* *} \mathrm{P}<0.01$ and ${ }^{* * * *} \mathrm{P}<0.0001$ vs. WT. RSK2, ribosomal S6 kinase 2; S19A, Ser19Ala; S19E, Ser19Glu; WT, wild type.

Akt is a serine/threonine kinase that is located at the center of the phosphatidylinositol-4,5-diphosphate 3-kinase (PI3K)/Akt pathway (40). Akt is a vital signaling node in cells, and it is also one of the most widely utilized protein kinases for human physiological activities (41). Akt plays an important role in numerous cellular activities, including cell proliferation, cell migration, angiogenesis, etc (42). Additionally, the activation of Akt and its related pathways is associated with tumorigenesis and poor prognosis (43). For instance, the amplification of three subtypes of Akt is detected in a variety of tumor cells, including colon, stomach, prostate and ovarian cancers $(44,45)$. Moreover, the overactivation of the PI3K/Akt pathway increased the number of cancer stem cells, promotes cancer cell metastasis and induces drug resistance $(46,47)$. In addition, the activity of the Akt/PI3K pathway regulates the growth, proliferation and survival of cells affecting the response of tumor cells to radiotherapy (48).

Histone H2A.X is a mutant of histone H2A and is widely expressed in the genome and is highly conserved among species (49). In the absence of histone H2A.X, gene stability is decreased and the susceptibility of cells to become cancerous increases, suggesting that $\mathrm{H} 2 \mathrm{~A}$.X may be a tumor suppressor (50). Weyemi et al (50) showed that the presence of H2A.X in colon cancer cells confers a strong ability to metastatic colonization, making the tumor invasive, and a high level of phosphorylation of H2A.X is one sign of a premalignant lesion and the early stages of cancer. Zhu et al and Dong et al $(33,51)$ found that the combination of a high phosphorylation of H2A.X at the Tyr142 or S139 sites and the RAS/ERK pathway in gastric cancer cells enhanced the apoptosis response caused by DNA damage, and increased the susceptibility of cancer cells to drug treatment. In addition, Livin/Baculoviral IAP repeat-contaning protein 7 induces the proliferation and migration of colon cancer cells by phosphorylating H2A.X at the Y39 site by the degradation of JMJD6 (28). Livin also increases the phosphorylation of H2A.X ${ }^{\mathrm{Y} 39}$ in lung cancer and breast cancer cells $(29,52)$. S16 is a newly reported phosphorylation site for H2A.X, and the phosphorylation of this site prevents the ubiquitination of the histone (33). Based on the aforementioned properties of Akt and H2A.X, the present study attempted to explore the relationship between these two molecules in breast cancer. Ultimately, it was demonstrated that knocking out or inhibiting Akt lead to an increase in H2A.X phosphorylation at S16 and that Akt was negatively associated with H2A.X.

To examine this interaction, the present work focused on RSK2, which is an important kinase of H2A.X. RSK2 controls several processes related to tumorigenesis, including proliferation, viability and motility (33). In addition, RSK2 promotes the invasion and metastasis of liver cancer and colon cancer, contributes to the survival of multiple myeloma cells and participates in the proliferation of prostate cancer cells and the development of c-fos-dependent osteosarcoma (53-55). Zhu et al (33) also suggested that RSK2-mediated phosphorylation of H2A.X increased the stability of H2A.X, thereby reducing the rate of cell transformation and inhibiting the onset of cancer. Thus, we hypothesized that Akt and RSK2 interacted with each other.

Supporting this hypothesis, Akt was found to phosphorylate RSK2 at S19, which inhibited H2A.X phosphorylation at 
S16. Then, it was established that Akt interacted with RSK2 and H2A.X. The Akt-mediated phosphorylation of RSK2 altered its substrate affinity to $\mathrm{H} 2 \mathrm{~A}$ and the expression level of certain transcription factors, including PSAT-1. This is important because the PSAT-1 factor was inhibited by the decrease of H2A.X S16ph that was mediated by the Akt-RSK2 pathway, and PSAT-1 is known to promote the survival and proliferation of cancer cells (56). Moreover, the present study further indicated that the survival and migration of breast cancer cells was promoted by the Akt-induced phosphorylation of RSK2 at S19, which inhibited the phosphorylation of H2A.X at S16.

In conclusion, the findings of the present study demonstrated that the interaction between Akt, RSK2 and H2A.X serves an important role in regulating the development of breast cancer. Specifically, Akt targets the phosphorylation of RSK2 at S19 to regulate the phosphorylation of histone H2A.X in breast cancer, which in turn, affects the survival and migration of breast cancer cells. Therefore, these molecules might be effective molecular targets for the treatment of breast cancer, providing another avenue for understanding the pathogenesis of breast cancer.

\section{Acknowledgements}

Not applicable.

\section{Funding}

No funding was received.

\section{Availability of data and materials}

All data generated or analyzed during this study are included in this published article.

\section{Authors' contributions}

ZFG designed experiments, drafted the initial manuscript and approved the manuscript. FLK performed the experiments and analyzed the experimental results. Both authors have read and approved the final manuscript.

\section{Ethics approval and consent to participate}

Not applicable.

\section{Patient consent for publication}

Not applicable.

\section{Competing interests}

The authors declare that they have no competing interests.

\section{References}

1. Yu Y, Luo W, Yang ZJ, Chi JR, Li YR, Ding Y, Ge J, Wang X and Cao XC: miR-190 suppresses breast cancer metastasis by regulation of TGF- $\beta$-induced epithelial-mesenchymal transition. Mol Cancer 17: 70, 2018
2. Liu BW, Yu ZH, Chen AX, Chi JR, Ge J, Yu Y and Cao XC: Estrogen receptor- $\alpha$-miR-1271-SNAI2 feedback loop regulates transforming growth factor- $\beta$-induced breast cancer progression. J Exp Clin Cancer Res 38: 109, 2019.

3. Ferlay J, Soerjomataram I, Dikshit R, Eser S, Mathers C, Rebelo M, Parkin DM, Forman D and Bray F: Cancer incidence and mortality worldwide: Sources, methods and major patterns in GLOBOCAN 2012. Int J Cancer 136: E359-E386, 2015.

4. van de Water W, Bastiaannet E, Dekkers OM, de Craen AJ, Westendorp RG, Voogd AC, van de Velde CJ and Liefers GJ: Adherence to treatment guidelines and survival in patients with early-stage breast cancer by age at diagnosis. Br J Surg 99: 813-820, 2012.

5. Duffy SW, Morrish OWE, Allgood PC, Black R, Gillan MGC, Willsher P, Cooke J, Duncan KA, Michell MJ, Dobson HM, et al: Mammographic density and breast cancer risk in breast screening assessment cases and women with a family history of breast cancer. Eur J Cancer 88: 48-56, 2018.

6. Derks MGM, Bastiaannet E, van de Water W, de Glas NA, Seynaeve C, Putter H, Nortier JWR, Rea D, Hasenburg A, Markopoulos C, Dirix LY, et al: Impact of age on breast cancer mortality and competing causes of death at 10 years follow-up in the adjuvant TEAM trial. Eur J Cancer 99: 1-8, 2018.

7. McPherson K, Steel CM and Dixon JM: ABC of breast diseases. Breast cancer-epidemiology, risk factors, and genetics. BMJ 309: 1003-1006, 1994.

8. Ursin G, Ma H, Wu AH, Bernstein L, Salane M, Parisky YR, Astrahan M, Siozon CC and Pike MC: Mammographic density and breast cancer in three ethnic groups. Cancer Epidemiol Biomarkers Prev 12: 332-338, 2003.

9. Vachon CM, van Gils CH, Sellers TA, Ghosh K, Pruthi S, Brandt KR and Pankratz VS: Mammographic density, breast cancer risk and risk prediction. Breast Cancer Res 9: 217, 2007.

10. Li X, Huang R, Ma L, Liu S and Zong X: Locoregional surgical treatment improves the prognosis in primary metastatic breast cancer patients with a single distant metastasis except for brain metastasis. Breast 45: 104-112, 2019.

11. Mamounas EP, Anderson SJ, Dignam JJ, Bear HD, Julian TB, Geyer CE Jr, Taghian A, Wickerham DL and Wolmark N: Predictors of locoregional recurrence after neoadjuvant chemotherapy: Results from combined analysis of National Surgical Adjuvant Breast and Bowel Project B-18 and B-27. J Clin Oncol 30: 3960-3966, 2012.

12. Holohan C, Van Schaeybroeck S, Longley DB and Johnston PG: Cancer drug resistance: An evolving paradigm. Nat Rev Cancer 13: 714-726, 2013

13. Kapoor PM, Lindstrom S, Behrens S, Wang X, Michailidou K, Bolla MK, Wang Q, Dennis J, Dunning AM, Pharoah PDP, et al: Assessment of interactions between 205 breast cancer susceptibility loci and 13 established risk factors in relation to breast cancer risk, in the Breast Cancer Association Consortium. Int J Epidemiol 49: 216-232, 2020.

14. Nguyen LV, Vanner R, Dirks P and Eaves CJ: Cancer stem cells: An evolving concept. Nat Rev Cancer 12: 133-143, 2012.

15. Chen W, Qin Y, Wang D, Zhou L, Liu Y, Chen S, Yin L, Xiao Y, Yao XH, Yang X, et al: CCL20 triggered by chemotherapy hinders the therapeutic efficacy of breast cancer. PLoS Biol 16: e2005869, 2018.

16. Sueoka T, Koyama K, Hayashi G and Okamoto A: Chemistry-driven epigenetic investigation of histone and DNA modifications. Chem Rec 18: 1727-1744, 2018.

17. Wang Z, Long H, Chang C, Zhao M and Lu Q: Crosstalk between metabolism and epigenetic modifications in autoimmune diseases: A comprehensive overview. Cell Mol Life Sci 75: 3353-3369, 2018

18. Dziaman T, Gackowski D, Guz J, Linowiecka K, Bodnar M, Starczak M, Zarakowska E, Modrzejewska M, Szpila A, Szpotan J, et al: Characteristic profiles of DNA epigenetic modifications in colon cancer and its predisposing conditions-benign adenomas and inflammatory bowel disease. Clin Epigenetics 10: 72, 2018.

19. Bhol CS, Panigrahi DP, Praharaj PP, Mahapatra KK, Patra S, Mishra SR, Behera BP and Bhutia SK: Epigenetic modifications of autophagy in cancer and cancer therapeutics. Semin Cancer Biol 66: 22-33, 2020.

20. Su J, Huang YH, Cui X, Wang X, Zhang X, Lei Y, Xu J, Lin X, Chen K, Lv J, et al: Homeobox oncogene activation by pan-cancer DNA hypermethylation. Genome Biol 19: 108, 2018. 
21. Zummeren MV, Kremer WW, Leeman A, Bleeker MCG, Jenkins D, Sandt MV, Doorbar J, Heideman DAM, Steenbergen RDM, Snijders PJF, et al: HPV E4 expression and DNA hypermethylation of CADM1, MAL, and miR124-2 genes in cervical cancer and precursor lesions. Mod Pathol 31: 1842-1850, 2018

22. Angulo JC, Andres G, Ashour N, Sanchez-Chapado M, Lopez JI and Ropero S: Development of castration resistant prostate cancer can be predicted by a DNA hypermethylation profile. J Urol 195: 619-626, 2016.

23. Abdel-Hafiz HA and Horwitz KB: Role of epigenetic modifications in luminal breast cancer. Epigenomics 7: 847-862, 2015.

24. Liu Y, Han S, Li Y, Liu Y, Zhang D, Li Y and Zhang J: MicroRNA-20a contributes to cisplatin-resistance and migration of OVCAR3 ovarian cancer cell line. Oncol Lett 14: 1780-1786, 2017.

25. Safdari Y, Khalili M, Ebrahimzadeh MA, Yazdani Y and Farajnia S: Natural inhibitors of PI3K/AKT signaling in breast cancer: Emphasis on newly-discovered molecular mechanisms of action. Pharmacol Res 93: 1-10, 2015.

26. Avanzato D, Pupo E, Ducano N, Isella C, Bertalot G, Luise C, Pece S, Bruna A, Rueda OM, Caldas C, et al: High USP6NL levels in breast cancer sustain chronic AKT phosphorylation and GLUT1 stability fueling aerobic glycolysis. Cancer Res 78: 3432-3444, 2018.

27. Khor TO, Gul YA, Ithnin H and Seow HF: Positive correlation between overexpression of phospho-BAD with phosphorylated Akt at serine 473 but not threonine 308 in colorectal carcinoma. Cancer Lett 210: 139-150, 2004.

28. Liu Y, Long YH, Wang SQ, Zhang YY, Li YF, Mi JS, Yu CH, Li DY, Zhang JH and Zhang XJ: JMJD6 regulates histone H2A.X phosphorylation and promotes autophagy in triple-negative breast cancer cells via a novel tyrosine kinase activity. Oncogene 38: 980-997, 2019.

29. Liu Y,Long YH, Wang SQ, Li YF and Zhang JH: Phosphorylation of H2A.X. ${ }^{\mathrm{Ty} r 39}$ positively regulates DNA damage response and is linked to cancer progression. FEBS J 283: 4462-4473, 2016.

30. Sharma A, Singh K and Almasan A: Histone H2AX phosphorylation: A marker for DNA damage. Methods Mol Biol 920: 613-626, 2012.

31. O'Connor MJ: Targeting the DNA damage response in cancer. Mol Cell 60: 547-560, 2015.

32. Weyemi U, Redon CE, Sethi TK, Burrell AS, Jailwala P, Kasoji M, Abrams N, Merchant A and Bonner WM: Twist1 and Slug mediate H2AX-regulated epithelial-mesenchymal transition in breast cells. Cell Cycle 15: 2398-2404, 2016.

33. Zhu F, Zykova TA, Peng C, Zhang J, Cho YY, Zheng D, Yao K, Ma WY, Lau AT, Bode AM and Dong Z: Phosphorylation of H2AX at Ser139 and a new phosphorylation site Ser16 by RSK2 decreases H2AX ubiquitination and inhibits cell transformation. Cancer Res 71: 393-403, 2011.

34. Qiu Q, Jiang J, Lin L, Cheng S, Xin D, Jiang W, Shen J and Hu Z: Downregulation of RSK2 influences the biological activities of human osteosarcoma cells through inactivating AKT/mTOR signaling pathways. Int J Oncol 48: 2508-2520, 2016.

35. Lee YJ, Bae JH, Kim SA, Kim SH, Woo KM, Nam HS, Cho MK and Lee SH: Cariporide Enhances the DNA damage and apoptosis in acid-tolerable malignant mesothelioma H-2452 cells. Mol Cells 40: 567-576, 2017.

36. Livak KJ and Schmittgen TD: Analysis of relative gene expression data using real-time quantitative PCR. Methods 25: 402-408, 2002.

37. Bassett JJ, Bong A HL, Janke EK, Robitaille M, Roberts-Thomson SJ, Peters AA and Monteith GR: Assessment of cytosolic free calcium changes during ceramide-induced cell death in MDA-MB-231 breast cancer cells expressing the calcium sensor GCaMP6m. Cell Calcium 72: 39-50, 2018.

38. Yang Q, Wen L, Meng Z and Chen Y: Blockage of endoplasmic reticulum stress attenuates nilotinib-induced cardiotoxicity by inhibition of the Akt-GSK3 $\beta$-Nox4 signaling. Eur J Pharmacol 822: 85-94, 2018.
39. Ravez S, Spillier Q, Marteau R, Feron O and Frederick R: Challenges and opportunities in the development of serine synthetic pathway inhibitors for cancer therapy. J Med Chem 60: 1227-1237, 2017.

40. Yang Q, Jiang W and Hou P: Emerging role of PI3K/AKT in tumor-related epigenetic regulation. Semin Cancer Biol 59: 112-124, 2019.

41. Zheng CH, Wang JB, Lin MQ, Zhang PY, Liu LC, Lin JX, Lu J, Chen QY, Cao LL, Lin M, et al: CDK5RAP3 suppresses Wnt/ $\beta$-catenin signaling by inhibiting AKT phosphorylation in gastric cancer. J Exp Clin Cancer Res 37: 59, 2018.

42. Searle EJ, Telfer BA, Mukherjee D, Forster DM, Davies BR, Williams KJ, Stratford IJ and Illidge TM: Akt inhibition improves long-term tumour control following radiotherapy by altering the microenvironment. EMBO Mol Med 9: 1646-1659, 2017.

43. Revathidevi S and Munirajan AK: Akt in cancer: Mediator and more. Semin Cancer Biol 59: 80-91, 2019.

44. Altomare DA and Testa JR: Perturbations of the AKT signaling pathway in human cancer. Oncogene 24: 7455-7464, 2005.

45. Engelman JA, Luo J and Cantley LC: The evolution of phosphatidylinositol 3-kinases as regulators of growth and metabolism. Nat Rev Genet 7: 606-619, 2006

46. Guerrero-ZotanoA,MayerIA and ArteagaCL:PI3K/AKT/mTOR: Role in breast cancer progression, drug resistance, and treatment. Cancer Metastasis Rev 35: 515-524, 2016.

47. Xie S, Yu X, Li Y, Ma H, Fan S, Chen W, Pan G, Wang W, Zhang H, Li J and Lin Z: Upregulation of lncRNA ADAMTS9-AS2 promotes salivary adenoid cystic carcinoma metastasis via PI3K/Akt and MEK/Erk signaling. Mol Ther 26: 2766-2778, 2018.

48. Starska K, Forma E, Lewy-Trenda I, Stasikowska-Kanicka O, Skora $\mathrm{M}$ and Brys $\mathrm{M}$ : Fibroblast growth factor receptor 1 and 3 expression is associated with regulatory PI3K/AKT kinase activity, as well as invasion and prognosis, in human laryngeal cancer. Cell Oncol (Dordr) 41: 253-268, 2018.

49. Redon CE, Nakamura AJ, Martin OA, Parekh PR, Weyemi US and Bonner WM: Recent developments in the use of $\gamma-\mathrm{H} 2 \mathrm{AX}$ as a quantitative DNA double-strand break biomarker. Aging (Albany NY) 3: 168-174, 2011.

50. Weyemi U, Redon CE, Choudhuri R, Aziz T, Maeda D, Boufraqech M, Parekh PR, Sethi TK, Kasoji M, Abrams N, et al: The histone variant $\mathrm{H} 2 \mathrm{~A} . \mathrm{X}$ is a regulator of the epithelial-mesenchymal transition. Nat Commun 7: 10711, 2016.

51. Dong C, Sun J, Ma S and Zhang G: K-ras-ERK1/2 down-regulates H2A.X ${ }^{\text {Y142ph }}$ through WSTF to promote the progress of gastric cancer. BMC Cancer 19: 530, 2019.

52. Ge Y, Liu BL, Cui JP and Li SQ: Livin promotes colon cancer progression by regulation of $\mathrm{H} 2 \mathrm{~A} . \mathrm{X}^{\mathrm{Y} 39 \mathrm{ph}}$ via JMJD6. Life Sci 234: 116788, 2019.

53. Yao K, Peng C, Zhang Y, Zykova TA, Lee MH, Lee SY, Rao E, Chen H, Ryu J, Wang L, et al: RSK2 phosphorylates T-bet to attenuate colon cancer metastasis and growth. Proc Natl Acad Sci USA 114: 12791-12796, 2017.

54. Lara R, Mauri FA, Taylor H, Derua R, Shia A, Gray C, Nicols A, Shiner RJ, Schofield E, Bates PA, et al: An siRNA screen identifies RSK1 as a key modulator of lung cancer metastasis. Oncogene 30: 3513-3521, 2011.

55. Kang S, Elf S, Lythgoe K, Hitosugi T, Taunton J, Zhou W, Xiong L, Wang D, Muller S, Fan S, et al: p90 ribosomal S6 kinase 2 promotes invasion and metastasis of human head and neck squamous cell carcinoma cells. J Clin Invest 120: 1165-1177, 2010.

56. RavezS,SpillierQ,MarteauR,FeronOandFrédérickR:Challenges and opportunities in the development of serine synthetic pathway inhibitors for cancer therapy. J Med Chem 60: 1227-1237, 2017.

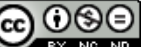

This work is licensed under a Creative Commons Attribution-NonCommercial-NoDerivatives 4.0 International (CC BY-NC-ND 4.0) License. 